\title{
Assessing Field-Specific Risk of Soybean Sudden Death Syndrome Using Satellite Imagery in Iowa
}

\author{
S. Yang, X. Li, C. Chen, P. Kyveryga, and X. B. Yang
}

First author: School of Life Sciences, Guizhou Normal University, Guiyang, 550001, China; first, second, third, and fifth authors: Department of Plant Pathology and Microbiology, Iowa State University, Ames, IA 50011; and fourth author: Iowa Soybean Association, Ankeny, IA 50023. Accepted for publication 3 April 2016.

\begin{abstract}
Yang, S., Li, X., Chen, C., Kyveryga, P., and Yang, X. B. 2016. Assessing field-specific risk of soybean sudden death syndrome using satellite imagery in Iowa. Phytopathology 106:842-853.

Moderate resolution imaging spectroradiometer (MODIS) satellite imagery from 2004 to 2013 were used to assess the field-specific risks of soybean sudden death syndrome (SDS) caused by Fusarium virguliforme in Iowa. Fields with a high frequency of significant decrease $(>10 \%)$ of the normalized difference vegetation index (NDVI) observed in late July to middle August on historical imagery were hypothetically considered as high SDS risk. These high-risk fields had higher slopes and shorter distances to flowlines, e.g., creeks and drainages, particularly in the Des

Moines lobe. Field data in 2014 showed a significantly higher SDS level in the high-risk fields than fields selected without considering NDVI information. On average, low-risk fields had 10 times lower $F$. virguliforme soil density, determined by quantitative polymerase chain reaction, compared with other surveyed fields. Ordinal logistic regression identified positive correlations between SDS and slope, June NDVI, and May maximum temperature, but high June maximum temperature hindered SDS. A modeled SDS risk map showed a clear trend of potential disease occurrences across Iowa. Landsat imagery was analyzed similarly, to discuss the ability to utilize higher spatial resolution data. The results demonstrated the great potential of both MODIS and Landsat imagery for SDS field-specific risk assessment.
\end{abstract}

In the major soybean producing states, such as Iowa, Illinois, and Indiana, soybean sudden death syndrome (SDS) caused by Fusarium virguliforme (Aoki et al. 2003) is considered the most important soybean fungal disease (Hartman et al. 2015; Wrather and Koenning 2009), causing yield losses up to 30 to $46 \%$ in years of great epidemics (Hartman et al. 1995). Typical symptoms of SDS include root rots in the vascular tissues, bluish fungal colonies visible on the surface of taproot near the soil surface, and, more important, interveinal chlorosis and necrosis in leaves, which cause premature defoliation of soybean (Navi and Yang 2008; Roy 1997; Roy et al. 1997).

Great efforts have been made in SDS research (Hartman et al. 2015; Roy et al. 1997). The pathogen is a slow-growing fungus but can survive well in the soil over years, living in crop residuals (Cho et al. 2001; Rupe et al. 1997). Abundant crop residuals favor the pathogen's survival, leading to the higher potential risks of infection and disease development (Yang and Navi 2010). Recent studies suggested that the pathogen could be isolated in other plants as well, without causing diseases or symptoms (Kolander et al. 2012). In soybean, $F$. virguliforme-infected plants can be symptomatic during the early growth stages (Njiti et al. 1998; Rupe et al. 1997). However, the expression of foliar symptoms during the late reproductive stages is the primary reason for substantial yield losses (Roy et al. 1997).

Although the complete understanding of SDS development is yet to be achieved, field observations and greenhouse experiments showed that the disease was favored by wet and cool (about $15^{\circ} \mathrm{C}$ ) soil environments during the early seedling stages (Leandro et al. 2013; Scherm and Yang 1996). SDS does not occur in every field or every year, given the variations of site-specific field and weather conditions. Overall disease development seems to be highly related to in-season weather patterns and planting time. After initial root

Corresponding author: X. Li; E-mail address: linuslee@iastate.edu

http://dx.doi.org/10.1094/PHYTO-11-15-0303-R

(C) 2016 The American Phytopathological Society infections, SDS foliar symptom expression normally appears after the excessive rainfall in summer (Leandro et al. 2013; Roy et al. 1997; Xing and Westphal 2006). In a dry year, even in a heavily $F$. virguliforme-infested field, SDS foliar symptom expression may not express at all. The disease is often more severe near river beds or poorly drained soils. Therefore, the risks of SDS in the field may vary significantly across different field conditions and combinations of certain environmental factors.

The management of SDS is difficult. SDS cannot be controlled by foliar fungicide applications. Roy et al. (1997) suggested that soil water draining could be used. The use of resistant varieties often fails with high disease pressure or is inconsistent at different locations (Hartman et al. 2015). Late planting could avoid the disease but with certain yield penalties and it is often impractical, as the disease does not always occur. Seed treatment to protect the roots from $F$. virguliforme infections was not available until the release of Bayer's new seed treatment fungicide product ILeVo in 2014 (Hartman et al. 2015; Wang et al. 2014). Although it is likely to achieve excellent control with seed treatment, it may not be necessary to treat seeds if the field does not have a high SDS risk, given the extra cost of seed treatment.

Previous studies have demonstrated that the risks of SDS occurrence could be assessed based on environmental factors at a regional scale (Scherm and Yang 1999). Given the new advances in the chemical control for this disease, farmers need more information for whether or not to use seed treatments in certain fields according to the field-specific SDS risks. However, it is extremely time-consuming to scout many fields to determine their disease risks. Therefore, we need tools that can help assess disease information or the risks of SDS across more fields.

Plant diseases may cause various changes in crop canopies, such as leaf lesions, blight, yellowing, and premature defoliation. These changes could be detected by measuring the electromagnetic radiation from the canopy, using certain instruments remotely, i.e., remote sensing (RS) (Jackson 1986; Knipling 1970). RS techniques are frequently utilized to acquire and retrieve certain field 
information to aid crop management, especially at large scales at which the efficacy and resources of human visual survey are limited (Nilsson 1995). Satellite imagery sources are the most important publicly accessible and well-calibrated RS data. With satellite imagery, plant canopy changes can be repeatedly and uniformly assessed across the entire targeted area. Furthermore, satellites can consistently collect and preserve information for long-term research, including historical information that may have been missed in an already finished field survey.

Although numerous studies have been conducted to assess crop information using satellite imagery (Asrar et al. 1984; Carlson and Ripley 1997; Daughtry et al. 1992; Esquerdo et al. 2011; Moran et al. 1997; Nguy-Robertson et al. 2012; Tucker 1979; Walthall et al. 2004), in plant disease management, satellite-based RS studies are still relatively scarce. Yet, with the fast-growing satellite RS technology, several studies have shown great potential for using satellite imagery to assess plant disease or disease-related information, and help disease management (Apan et al. 2004; Ashourloo et al. 2014a; Franke and Menz 2007; Jones 2014; Li et al. 2015; Martinelli et al. 2014; Mirik et al. 2011; Moran et al. 1997).

A common use of RS in plant sciences is to derive vegetation indices from spectral reflectance as representations of plant health status (Jackson 1986; Knipling 1970). Vegetation indices could differentiate vigorous plants from stressed or diseased plants. The normalized difference vegetation index (NDVI) is one of the most widely used vegetation indices, and NDVI is sensitive to the leaf area index and biomass (Carlson and Ripley 1997). NDVI is derived from red and near infrared (NIR) bands by the following equation: NDVI = (NIR - RED)/(NIR + RED). Franke and Menz (2007) used NDVI for wheat disease detection at a field level. Ashourloo et al. (2014b) reported NDVI among the best performance indices for wheat rust classification. Rumpf et al. (2010) found that NDVI alone did not classify adequately, but combination of different vegetation indices achieved classification of three beet diseases with high accuracy.

In soybean, Nutter et al. (2010) used high resolution $(1 \mathrm{~m})$ IKONOS satellite imagery to characterize spatial patterns of NDVI changes caused by soybean rust (causal agent Phakopsora pachyrhizi) and Cercospora leaf blight (causal agent Cercospora kikuchii) at the field level. However, using high-resolution commercial imagery to assess diseases for row crops is not economical or practical due to the high costs. Fortunately, other fast updated satellite data are publicly available at lower spatial resolutions with no extra costs. For example, rapidly updated satellite imagery is available from Landsat systems and AQUA-TERRA systems at 30- and 250-meter resolution, respectively. It was found that even at $250-\mathrm{m}$ resolution NDVI data from MODIS (the moderate resolution imaging spectroradiometer) on AQUA-TERRA satellites may still be useful for monitoring significant canopy changes caused by diseases or floods in soybean fields (Li and Yang, 2013). On the other hand, MODIS on AQUA-TERRA systems can provide fast updated data for a region in a few days. A temporal assessment at a lower spatial resolution is certainly better than one snapshot at a finer resolution, because the latter cannot detect temporal canopy changes due to disease occurrence. However, use of low-resolution MODIS satellite imagery for soybean disease risk assessment is scarce.

Given the annual and field-level variations of SDS occurrence, it is more important to know the SDS risks in a field in advance so that appropriate disease management, such as seed treatment, can be adopted before planting. Since SDS is favored by cool and wet soil in spring and excessive rainfall in summer (Leandro et al. 2013), a field with high SDS risks would highly likely tend to have other foliar diseases, such as brown spot, downy mildew, and white mold, in the long run. Thus, hypothetically, a general measurement of NDVI changes due to soybean foliar diseases and their historical patterns may provide certain information for the risks of SDS, even if we do not have an established relationship specifically for the soybean NDVIs and SDS. Besides weather factors, other field-specific factors, such as corn residue from the previous season (Yang and Navi 2010), soil type, and terrain feature, may likely also affect SDS occurrence. Therefore, we hypothesize that NDVI derived from satellite imagery at a low resolution, such as those from Landsat and AQUA-TERRA systems, could be used to assess field-specific SDS risks along with information of other factors related to SDS occurrence. The objectives of this study were to examine the characteristics of historical NDVI changes during the late stages of soybean growth and identify the relationships among historical NDVIs, weather, and field environmental factors, and SDS risks in the field across selected regions in Iowa.

\section{MATERIALS AND METHODS}

Satellite and other related data. We extracted weekly eMODIS NDVI imagery at 250-m resolution for Iowa from 2004 to 2014, using the United States Geological Survey (USGS) EarthExplorer online data server (http://earthexplorer.usgs.gov/) (Jenkerson et al. 2010), which provides both calibrated historical and current season data with consistent quality control. July and August NDVI were collected for the period of 2004 to 2013 and April to August NDVI for 2014. Historical surface NDVI data at 30-m resolution in July and August during 2002 to 2014, derived from the imagery acquired from Landsat 5 (Landsat thematic mapper, ETM, 1985-2013) and 7 (Landsat enhanced thematic mapper plus, ETM+, 1999 to present) were also ordered from the USGS Earth Resources Observation and Science (EROS) Center Science Processing Architecture. Due to a longer revisiting time (16 days) of Landsat systems and the failure of the Scan Line Corrector in Landsat 7, causing about 22\% data missing in each scene, Landsat NDVI data do not have a spatial and temporal coverage range as good as eMODIS data for all the studied areas. Therefore, these data were used only for comparisons with the results of eMODIS data in very limited areas when available.

Crop history data were from the Cropland Data Layer (USDA National Agricultural Statistics Service Cropland Data Layer 2014) at 30-m resolution. National elevation data (NED) of spatial resolution of 1 arc-second (about $30 \mathrm{~m}$ ) were also obtained from the USGS EarthExplorer (Gesch et al. 2002; Gesch 2007). High-resolution flowline, e.g., river, creek, and ditch, data were obtained as well (National Hydrography Dataset, Flowlines with Hydrologic Significance in Iowa, USGS). ArcGIS (Esri, Redlands, CA) was used to process the RS data and other related datasets for analyses.

Along with the current season eMODIS NDVI data, we retrieved site observational data of other environmental variables, including monthly accumulated precipitation, monthly maximum, and monthly minimum temperature from April to July from Iowa Environmental Mesonet (IEM) (http://mesonet.agron.iastate.edu). We used temperatures and precipitation measured from the nearest station to our sampling locations. To generate the risks maps based on disease risk models developed with the disease survey data, we also retrieved statewide gridded reanalysis weather data (spatial resolution at 0.25 degree of longitude/latitude) of these variables from IEM. A BILINEAR resampling was performed for each of the gridded weather variable to generate a 250 meter resolution data layer.

Temporal analysis and field characterization based on historical NDVI data in four regions in Iowa. We focused on four regions (A, B, C, and D [Fig. 1]) covering major soybean planting areas in Iowa. Each region was $100 \times 100 \mathrm{~km}$ in size. The early expression of foliar symptoms of SDS in severely diseased plants, generally appearing in late July to middle August with concomitant reduction of healthy leaf tissues, will cause NDVI reduction, whereas the green leaf area index (gLAI) of a healthy rainfed soybean canopy undergoing natural losses of canopy vigor or senescence will increase slightly (or remain stable) in August, according to a multiyear study conducted in Nebraska, a state adjacent to Iowa with similar soybean and corn cropping systems (Nguy-Robertson et al. 2012). Since we used weekly eMODIS satellite imagery to analyze the temporal changes of NDVI, the data 
collected in the last week of July and the first two weeks of August would cover this key disease development period. During this period, the changes of NDVIs would reflect the canopy damages caused by the foliar diseases, including SDS. Specifically, the NDVIs in the last week of July were subtracted from the NDVIs in the second week of August to show the changes of NDVIs during 2 weeks.

Furthermore, Nguy-Robertson et al. (2012) found that gLAIs of rainfed soybean canopy were around 3.5 in August. They found that NDVI followed a curve of NDVI $=(1.03+0.37 \mathrm{gLAI})^{-1.9}$ in association with gLAI changes. Assuming soybean gLAI reaches 3.5 in late July, its NDVI is then 0.944 . If the canopy is damaged causing a $10 \%$ NDVI decrease from 0.944 to 0.849 , then gLAI would have a decrease to 2.43 , about $30 \%$ loss of healthy leaf tissues.

Based on previous field surveys and NDVI changes observed during the 2010 growing season, when SDS had an outbreak in Iowa, we arbitrarily chose a $10 \%$ reduction of NDVI during this 2 -week period as the threshold to determine if a field had a significant loss of healthy leaf vegetation. Using historical soybean NDVI satellite imagery and crop information from the Cropland Data Layer in 2004 to 2013 for each field, the frequency of years that had $10 \%$ or greater NDVI decrease in this period was determined. Considering soybean-corn rotation, we generated an NDVI change frequency statistic, Freq_Even for the fields that had soybean planted in evennumbered years, i.e., 2004, 2006, ...2012, with other crops, usually corn, planted in odd-numbered years. This provided a relatively uniform subsample of soybean fields with similar rotation history to reduce the variation from crop rotations. Because of different field size, a pixel $(250 \times 250 \mathrm{~m})$ in a NDVI map may actually reflect the NDVI of a mixture of crops planted in fields of various sizes. To ensure that the NDVI was from soybean fields, the generated Freq_Even maps were aligned to the crop layer data map and only pixels with soybean field coverage greater than $90 \%$ were used in analyses.

Previous field observations suggested that fields with severe SDS occurrences were often in rolling (sloping) areas or near flowlines or water bodies, where saturated soil moisture or floods would be more likely to occur (Hartman et al. 2015). To examine the fieldspecific characteristics that had high frequency of NDVI reduction, we performed a near analysis, using ArcGIS to calculate the distance to the nearest flowlines (DNF) of each field, i.e., a pixel in eMODIS imagery, in the four regions. Similarly, slope of each pixel was determined using ArcGIS with the corresponding NED data. Preliminary analyses showed that the distributions of DNF and slope were skewed, even after a logarithmic transformation. Therefore, these data were analyzed using one-way analysis of variance (ANOVA) with the Wilcoxon/Kruskal-Wallis's nonparametric test to examine differences among different Freq_Even frequency values. The statistical analyses were performed using SAS (SAS Institute, Cary, NC).

Disease field surveys. In-season field surveys were conducted during early August to early September in 2014. We selected three groups of fields, based on different historical information. Among the fields with high values of Freq_Even (e.g., 2, 3, or 4 of 5 years), we surveyed 34 fields (group $\mathrm{H}$ ) across the four regions (Fig. 1). These fields were treated as high SDS risk fields, likely associated with either high SDS occurrence, high pathogen ( $F$. virguliforme) density, or both.

A group of 28 fields (group R) were selected by Iowa Soybean Association (ISA) on-farm network staff to conduct on-farm replicated strip trials in recent years, chosen without considering their historical NDVI changes, although some might have experienced severe but unconfirmed soybean foliar disease occurrences, based on aerial imagery taken in late August. We treated this group of fields as a control group, though not a strictly random selection. In the 2014 season, 26 of these fields were planted with soybean and two were corn fields.

Further, we selected a group of fields (group L) that had corn planted in 2012 and also a significant decrease $(>15 \%)$ of canopy NDVI during the 2 weeks from late July to middle August in that year. It is well-known that corn is very sensitive to drought. Iowa experienced a severe drought in summer 2012 and many corn fields suffered water stress, causing loss of green tissues (Al-Kaisi et al.

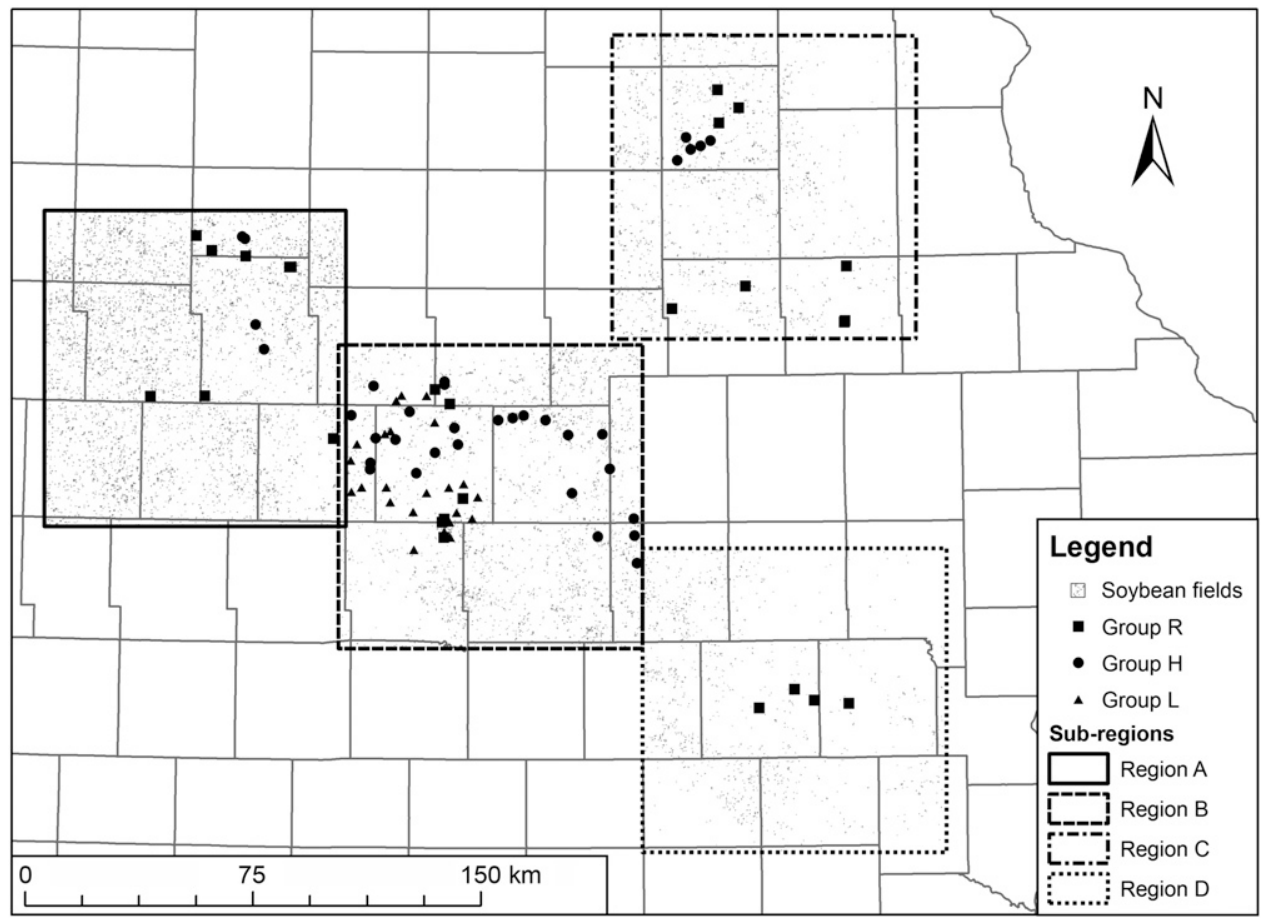

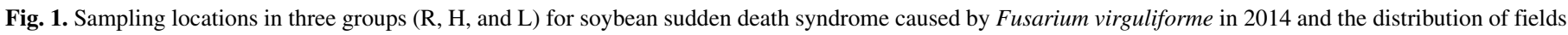

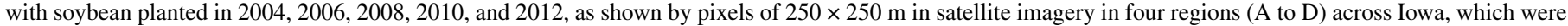
used for the analysis of temporal changes of historical soybean canopy normalized difference vegetation indices in early August. 
2013). According to Nguy-Robertson et al. (2012), gLAI of rainfed corn canopy reaches to 4 in early July then gradually decreases to 3.5 in mid-August. The changes of corn NDVI followed NDIV = $0.94-0.73 \times 0.6^{\mathrm{gLAI}}$ in response to gLAI changes. Therefore, in late July to early August, a 15\% NDVI decrease in corn canopy would imply a rapid loss of about $40 \%$ green tissues. As the corn fields in group L had >15\% NDVI decrease in early August 2012, it would highly likely indicate severe drought stresses in these fields.

The corn fields that were water stressed in a drought year would tend to be dry in soil conditions in a normal year as well. As SDS favors wet soil conditions, we hypothesized that these corn fields would have very low $F$. virguliforme density compared with fields with excessive moisture. Finally, 11 fields were sampled in group L. For group $\mathrm{H}$ and group $\mathrm{R}$, all together by region, 12 fields were surveyed in region $\mathrm{A} ; 31$ in region $\mathrm{B}$ for being closer to the university's campus; 13 in region $\mathrm{C}$, and four in region $\mathrm{D}$. group $\mathrm{L}$ was in region B only.

In each field, the surveyed area was a square about $250 \times 250 \mathrm{~m}$ spatially aligned and covered by a single pixel of MODIS satellite imagery to ensure maximum matching of field survey and satellite data. Within this survey area, disease readings or soil samples, or both, were taken from five locations arranged in an ' $X$ ' pattern across the area, with 100 to $150 \mathrm{~m}$ distance between any two adjacent locations. At each location, the disease was surveyed in an area of $3 \times$ $3 \mathrm{~m}$. SDS level of the field was simply classified from 0 to 3 , based on visual assessment of incidence and severity averaged across the five sampling locations. Incidence was defined as the percentage of diseased plants in the sampling area, and severity as the percentage of leaf area showing interveinal chlorosis and necrosis in the diseased plants. SDS occurrence level (SOL) of a field was rated in an ordinal scale of 0 to 3: 0 for no foliar SDS symptom observed, 1 for SDS incidence less than 10\%, 2 for incidence in 10 to $30 \%$ and severity less than $30 \%$, and 3 for incidence higher than $30 \%$ or incidence in 10 to $30 \%$ and severity higher than $30 \%$. Soil samples from 0 to $15 \mathrm{~cm}$ of surface layer between two arbitrarily selected rows was taken from each of the five locations in each field and was mixed together prior to DNA extraction and $F$. virguliforme quantification via quantitative polymerase chain reaction (qPCR). The 60 fields were surveyed differently. For group H, only SOL was recorded. For group R, both soil samples and disease reading were taken. For group L, only soil samples were collected, as the crop was corn.

Total DNA extraction from soil samples. To determine the pathogen density in the sampled soil, we used qPCR to estimate $F$. virguliforme density. We also collected soil samples from a research plot with severe SDS occurrence at Hinds research farm in Ames, Iowa to test the $F$. virguliforme density and this density was used as a standard as a high $F$. virguliforme density level.

Soil samples were frozen at $-20^{\circ} \mathrm{C}$ immediately after sampling. Prior to DNA extraction, these samples were allowed to thaw overnight under $4^{\circ} \mathrm{C}$. Soil inside each sample bag was then mixed thoroughly and approximately $5 \mathrm{~g}$ of soil was transferred into a $15-\mathrm{ml}$ falcon tube containing $5 \mathrm{ml}$ of sterile water. After mixing for $10 \mathrm{~min}$ at $250 \mathrm{rpm}$ in a shaker, an aliquot of $0.25 \mathrm{ml}$ slurry (corresponding to 0.2 to $0.3 \mathrm{~g}$ of soil) was transferred into a bead tube provided by the PowerLyzer PowerSoil DNA isolation kit (MO BIO Laboratories, Inc., Carlsbad, CA). The DNA was extracted following the protocol of the manufacturer, with the homogenization step set at 4,000 rpm for 2 min to ensure thorough release of DNA from fungal propagules. DNA concentration was estimated using a NanoDrop 8000 Spectrophotometer (Thermal Scientific, Wilmington, DE). Each DNA sample was further diluted (10 and $100 \times$ dilution) prior to its use as template for qPCR analysis.

Estimation of $F$. virguliforme populations, using qPCR with primers and probes highly specific to $F$. virguliforme. For qPCR quantification of the $F$. virguliforme population, we targeted the FvToxl gene, which is unique to SDS pathogens including $F$. virguliforme and closely related Fusarium species (Brar et al. 2011). FvToxl gene is present as a single-copy gene in
F. virguliforme (Wang et al. 2015), allowing us to estimate the $F$. virguliforme cell number (an approximate of the population) in individual soil samples through the quantification of FvToxl. A highly specific qPCR system targeting the FvToxl gene has recently been developed for the detection of $F$. virguliforme DNA from soil samples (Kandel et al. 2015; Mbofung et al. 2011). We further optimized this qPCR assay system by choosing thermodynamically favorable primers and the probe near the $5^{\prime}$ end of the FvToxl gene, which appears to be slightly less conserved than the previous primers or probe set (Mbofung et al. 2011) and allows the detection of all SDS-causing Fusarium spp. Specifically, we selected forward primer (CTGAGGAGTACGATCCAGAGAA) and reverse primer (TAGCGATGGGTGTTGTTGAG) with a dual-labeled probe (AGG CACGCTGGAATGGTAAGGATT) that was labeled with 5' 6-FAM, internal ZEN quencher, and 3' Iowa Black FQ quencher (Integrated DNATechnologies, Inc., Coralville, IA). The qPCR was carried out in a $10-\mu l$ total reaction volume using KAPA PROBE FAST Universal $2 \times$ qPCR master mix (Kapa BioSystems, Wilmington, MA), with the following thermal profile: $5 \mathrm{~min}$ at $95^{\circ} \mathrm{C}$ followed by 40 cycles of $3 \mathrm{~s}$ at $95^{\circ} \mathrm{C}$ and $45 \mathrm{~s}$ at $60^{\circ} \mathrm{C}$ (Opticon-2 thermal cycler, Bio-Rad Laboratories, Hercules, CA). Each sample was tested at three concentrations $(10,100$, and 1,000× dilution).

We took advantage of the availability of gBlocks gene fragments from Integrated DNA Technologies and synthesized a fragment of FvToxl with absolute (precise) concentration; such a doublestranded DNA fragment was used to prepare a series of 10-fold dilutions, ranged from 0.00001 to $100 \mathrm{pM}$, with representative concentrations included as a standard for each qPCR run. The amplification threshold was manually set to minimize background fluorescence for better estimation of cycle threshoild (or quantitation cycle) values. The linear regression equation obtained with the standard in each qPCR run was used to estimate $F$. virguliforme population from each DNA sample representing different soil samples.

The qPCR assay we developed could detect $F$. virguliforme as well as closely related Fusarium species, including F. azukicola, F. brasiliense, F. cuneirostrum, F. phaseoli, and F. tucumaniae, that are known to cause SDS on soybean or other bean hosts (Aoki et al. 2012; Hughes et al. 2014). Since the latter group has not been found in the United States, we assumed that the SDS-causing Fusarium populations we detected with our qPCR assay were $F$. virguliforme. For each soil sample with positive $F$. virguliforme detection, isolating for $F$. virguliforme was conducted, following a previously described method (Cho et al. 2001), in order to test their pathogenicity in a greenhouse on 'William 82', an SDS-susceptible soybean.

Statistical analyses and modeling for disease data. Because SOL data in groups $\mathrm{H}$ and $\mathrm{R}$ were in an ordinal scale, we used oneway ANOVA with Wilcoxon/Kruskal-Wallis's nonparametric test to examine the SOL difference between the two groups. The null hypothesis was that the two groups had equal means. In our case, the alternative hypothesis was that the SOL in group $\mathrm{H}$ was higher than that in group $\mathrm{R}$, since the fields in group $\mathrm{H}$ were selected based on their high Freq_Even values, an index for high disease risks. For the differences of slope and DNF in the three groups, Wilconxon/Kruskal-Wallis's test was also used, given their nonnormal distributions. The $F$. virguliforme densities in groups $\mathrm{R}$ and $\mathrm{L}$ were analyzed using Welch's $t$ test to compare the means, assuming normal distributions with unequal variances. Correlations of SOL and $F$. virguliforme density values across the fields in group $\mathrm{R}$ were estimated as well. These analyses were performed using SAS (SAS Institute).

The disease data from all surveyed soybean fields were pooled together for modeling. First, correlations of SOL with other environmental factors and NDVI values were determined, using both linear correlation and nonparametric Spearman correlation coefficients. The factors included were the log-transformed DNF (log_DNF) and slope (Log_slope), NDVIs in June, as well as monthly precipitation and minimum and maximum temperatures in April to July (Table 4). It must be noted that even the 
log-transformed DNF and slope were still not statistically normal in distributions. However, after the logarithmic transformation, they were close to normal and symmetric and we treated them as normal variables in the analysis.

SDS occurrence level as a response to environmental factors and NDVI variables were related, using ordinal logistic regression (OLR) (Hosmer et al. 2013) and an ordinal regression tree (Galimberti et al. 2012) to examine and differentiate the effects of key factors to SDS occurrence. OLR treats SDS occurrence level as a dependent variable and fits the cumulative probabilities of the response categories, i.e., SOL to the independent explanatory variables. For $k+1$ ordinal values of response categories, the cumulative model has the form of $g$ $[\operatorname{Pr}(Y \leq i \mid x)]=\alpha_{i}+\beta^{\prime} x, i=1, \ldots, k$, in which $\alpha$ is the vector of $k$ intercept parameters for response categories, and $\beta$ is the vector of slope parameters for the $x$ independent variables, i.e., the environmental factors and NDVI variables in this case. The LOGISTIC Procedure in SAS (SAS Institute) was used to perform the OLR regression and the parallel slopes assumption was examined by the score tests. For the best model selection, first, all variables were put into the model, and then, a backward elimination was used to select the best candidate models with significant effect at 0.05 . Because some of these variables showed strong linear correlations (results not shown) with each other, highly correlated variables in the candidate models were further selected arbitrarily based on their significance level and biological meaning to SDS occurrence.

The regression tree analyses were run with the total misclassification rate option for tree pruning and squared differences in scores option for tree splitting (Galimberti et al. 2012). The one standard error rule was adopted to acquire final optimal size tree (Breiman et al. 1984). The regression tree statistical analyses were conducted in R (R Development Core Team 2014) with the packages MASS (Venables and Ripley 2002), rpartScore (Galimberti et al. 2012), Effects (Fox 2003; Fox and Hong 2009), and Rattle (Williams 2011).

\section{RESULTS}

Temporal analysis and field characterization based on historical NDVI data in four regions in Iowa. The fields (pixels in satellite imagery) with different Freq_Even values in the four regions were mapped in Figure 1. The numbers of fields in each value of Freq-Even within a region and their corresponding percentage to the total number of fields are given in Table 1 . The highest Freq-Even value was 4, out of five even-numbered years of soybean planting. Obviously, region A had the highest total number of soybean fields and D had the lowest number of fields. Also, region A had relatively more fields with high Freq-Even value $(\geq 2)$ than the other regions, especially region D.

The results of near analysis for DNF of a field and slope values are given in Table 2. Overall, the fields in region A had a greater DNF (>600 $\mathrm{m}$, on average) than the fields in the other regions. More specifically, in region A, the fields with high value of Freq_Even had a significantly shorter distance to a flowline than the other fields, based on the Wilcoxon test $(P<0.001)$. In region $\mathrm{B}$, this trend was less striking, but a statistic difference was still evident between Freq_Even $=0$ and Freq_Even $=1$ and $\geq 2(P<0.001)$. In regions
C and D, no significant trends were detected for DNF. For slope, there was also a strong tendency in region A that the fields with higher Freq_Even had a significantly higher slope value $(P<0.001)$. In regions $\mathrm{B}$ and $\mathrm{D}$, this trend was not as striking as that in region $\mathrm{A}$, but significant differences still existed as well. In region $C$, no significant differences of slope were detected among the fields with different Freq_Even values.

Disease field surveys. Among the 60 soybean fields, 48 showed various degrees of SDS symptoms. The highest incidence was about $80 \%$ and severity was about $30 \%$. Region A had 12 fields and 11 had SDS foliar symptoms detected, with an average SOL of 1.58. Region B had 31 fields and 26 had SDS foliar symptoms, with an average SOL of 1.80. The region with the lowest average SOL was in northeastern Iowa, i.e., region $\mathrm{C}$, with the prevalence at about $53.85 \%$ and average SOL at 0.77 . All four fields surveyed in region $\mathrm{D}$ had SDS occurrence, at 1.75 on average. Table 3 shows the field survey summaries by group and Table 4 shows linear and rank (Spearman) correlation values of SOL in all 60 surveyed soybean fields, with several environmental factors and NDVI values. The average SOL in group $\mathrm{H}$ was 1.73 , significantly higher $(P=0.046)$ than that (at 1.27) in group $\mathrm{R}$, given the alternative hypothesis of SOL in group $\mathrm{H}>\mathrm{SOL}$ in group $\mathrm{R}$.

The average slope in group $\mathrm{H}$, group $\mathrm{R}$, and group $\mathrm{L}$ was 1.27 , 1.04 , and 0.94 degrees, respectively (Table 3 ). Wilcoxon's tests did not detect significant differences in mean slope values among the three groups. Yet, SDS seemed more severe in fields with rolling topography, according to a weak positive linear correlation of SOL with log_Slope $(r=0.216, P=0.098)$ in Table 4 . Similarly, although, on average, the fields in group $\mathrm{H}$ had a much shorter average DNF $(350.75 \mathrm{~m})$ to than those in groups $\mathrm{R}(492.49 \mathrm{~m})$ and $\mathrm{L}(482.44 \mathrm{~m})$, the statistical differences were not significant $(P=0.254)$. However, Spearman's $\rho$ detected a significant negative correlation of SOL and $\log$ _DNF, i.e., fields closer to a flowline had higher levels of SOL.

In group $\mathrm{R}$, only one corn field had negative $F$. virguliforme detection according to qPCR tests, while in group L, two fields had negative $F$. virguliforme detection. The average and highest F. virguliforme density in group $\mathrm{R}$ were 49,984 and 141,542,

TABLE 2. Summary of near and slope analyses for fields with Freq_Even values in the four regions

\begin{tabular}{lrrrr}
\hline & \multicolumn{4}{c}{ Distance (meters) to the nearest flowline and slope (degrees) } \\
\cline { 2 - 5 } Region & \multicolumn{1}{c}{0} & \multicolumn{1}{c}{1} & \multicolumn{1}{c}{$\geq 2^{\mathrm{x}}$} & $P$ value \\
\hline A & $689.45 \mathrm{a}^{\mathrm{z}}$ & $659.03 \mathrm{~b}$ & $606.28 \mathrm{c}$ & $<0.001$ \\
& $0.92 \mathrm{a}$ & $0.96 \mathrm{~b}$ & $1.08 \mathrm{c}$ & $<0.001$ \\
$\mathrm{~B}$ & $385.85 \mathrm{a}$ & $332.34 \mathrm{~b}$ & $332.98 \mathrm{~b}$ & $<0.001$ \\
& $1.62 \mathrm{a}$ & $1.79 \mathrm{~b}$ & $1.78 \mathrm{~b}$ & $<0.001$ \\
$\mathrm{C}$ & $300.97 \mathrm{a}$ & $301.66 \mathrm{a}$ & $307.52 \mathrm{a}$ & 0.999 \\
& $1.26 \mathrm{a}$ & $1.23 \mathrm{a}$ & $1.22 \mathrm{a}$ & 0.179 \\
D & $275.20 \mathrm{a}$ & $272.01 \mathrm{a}$ & $260.00 \mathrm{a}$ & 0.972 \\
& $1.70 \mathrm{a}$ & $1.67 \mathrm{a}$ & $2.01 \mathrm{~b}$ & 0.034 \\
\hline
\end{tabular}

$\mathrm{x}$ All fields with Freq_Even values $\geq 2$ were pooled together for analysis of variance, due to limited sample size.

y $P$ values for the $\chi^{2}$ approximation of Wilcoxon/Kruskal-Wallis one-way test.

${ }^{\mathrm{z}}$ Nonparametric comparisons for each pair of Freq_Even values using Wilcoxon method. Different letters indicating significant difference of medians of the corresponding variable.

TABLE 1. Summary of Freq_Even ${ }^{z}$ results in soybean fields in four regions across Iowa

\begin{tabular}{|c|c|c|c|c|c|c|}
\hline Region & \multicolumn{6}{|c|}{ Count of fields of each Freq_Even value (percentage of the total) } \\
\hline A & $16,517(67.02)$ & $7,052(28.62)$ & 970 (3.94) & $96(0.39)$ & $7(0.03)$ & 24,642 \\
\hline $\mathrm{C}$ & $9,887(81.29)$ & $2,066(16.99)$ & $201(1.65)$ & $9(0.07)$ & $0(0)$ & 12,163 \\
\hline D & $6,546(82.75)$ & $1,271(16.06)$ & 91 (1.15) & $3(0.04)$ & $0(0)$ & 7,911 \\
\hline
\end{tabular}

${ }^{\mathrm{z}}$ Freq_Even: frequency of significant decrease $(>10 \%)$ of the normalized difference vegetation index (NDVI) of soybean in late July to middle August in evennumbered years from 2004 to 2013, based on eModis NDVI imagery data at 250-meter resolution from the United States Geological Survey. 
respectively, while in group $\mathrm{L}$, they were 3,775 and 10,086 , respectively. A significant difference $(P<0.001)$ of mean $F$. virguliforme density was detected between groups $\mathrm{R}$ and $\mathrm{L}$, based on Welch $t$ test (Table 3). In group R, a high level SDS occurrence was associated with a relatively high $F$. virguliforme density, though they were only weakly positively correlated $(r=0.108)$. However, fields with high $F$. virguliforme density may not always have high SOL in individual fields (results not shown). In comparison, the $F$. virguliforme density at Hinds research farm, used as a reference for high level $F$. virguliforme density, where $F$. virguliforme was often added as an inoculum for SDS research, was estimated at 80,162 cells per gram of soil. By region, the average $F$. virguliforme density was 57,649 in region $A, 66,272$ in region $B, 58,863$ in region $C$, and 14,422 in region D. The highest $F$. virguliforme density $(141,542)$ occurred in region $\mathrm{C}$ in northeastern Iowa, yet with moderate SDS (SOL at 2) symptoms observed. From the soil samples, eight $F$. virguliforme isolates were obtained and all showed similar pathogenicity in the greenhouse test on 'William 82', causing typical root rot and foliar SDS symptoms (results not shown).

Statistical analyses and risk prediction. Table 4 lists all variables that had significant correlations $(P<0.1$, based on linear correlation or Spearman rank correlation) with SOL. NDVI values collected from June 16 to 30 all showed significant and consistent correlations with SOL, and their average, Jun_NDVI, showed even higher correlation (Table 4). As mentioned before, both logtransformed slope and DNF showed relatively significant correlations, log-slope was positively correlated and $\log$ _DNF was negatively correlated to SOL. Positive and consistent correlations were found between SOL and spring maximum temperatures (AprTx and MayTx) as well as the minimum temperature of July (JulTn). For precipitation, only in July, a relatively significant correlation was identified, while the precipitation in June seemed to have a weak negative effect to SOL. Other environmental factors did not show significant correlation with SOL.

Because of the consistent and significant correlations of NDVIs from June 16 to 30 with SOL, we used their average, Jun_NDVI, in the logistic regression analysis. Backward selection (significance criteria level, $P=0.05$ ) reduced the original full model to model 1 , including variables log_slope, Jun_NDVI, MayTx, and JunTx (Table 5). In this model, JunTx had a different effect to SDS compared with the other variables (Fig. 2). Specifically, high JunTx tended to reduce SDS occurrence, while high values of the other three variables tended to increase disease occurrence. In Figure 2, the odds ratio and profiler of JunTx indicated a strong effect of JunTx to SOL. Because MayTx was highly correlated with JunTx ( $r=0.8067$ ), model 1 was further reduced by removing JunTx arbitrarily, resulting in model 2 (Table 5). The two models showed similar goodness of fit with percent concordant at $78.8 \%$ (model 1) and $72.5 \%$ (model 2 ), which indicated high predictive accuracy. The score tests for the proportional odds assumption of both models were nonsignificant, i.e., $P>0.05$, indicating satisfaction of parallel slopes assumption.

With the IEM gridded weather data of MayTx and JunTx in 2014, an SDS risk map covering all the subregions was generated based on

TABLE 5. Results of ordinal logistic regression for identifying the probability of occurrence level of sudden death syndrome caused by Fusarium virguliforme in response to other factors ${ }^{\mathrm{z}}$

\begin{tabular}{llrrrrc}
\hline Models & \multicolumn{1}{c}{ Term } & Estimate & $\begin{array}{c}\text { Standard } \\
\text { error }\end{array}$ & \multicolumn{1}{c}{$\chi^{2}$} & $P>\chi^{2}$ & $\begin{array}{c}\text { Odds } \\
\text { ratio }\end{array}$ \\
\hline Model 1 & Intercept[0] & 15.099 & 12.062 & 1.567 & 0.211 & - \\
& Intercept[1] & 16.987 & 12.111 & 1.968 & 0.161 & - \\
& Intercept[2] & 18.718 & 12.148 & 2.374 & 0.123 & - \\
& Log_slope & -3.412 & 1.163 & 8.606 & 0.003 & 0.033 \\
& Jun_NDVI & -10.270 & 3.211 & 10.230 & 0.001 & $<0.001$ \\
& MayTx & -4.192 & 1.210 & 12.010 & 0.001 & 0.015 \\
Model 2 2 JunTx & 2.972 & 1.005 & 8.751 & 0.003 & 19.523 \\
& Intercept[0] & 26.044 & 11.183 & 5.424 & 0.020 & - \\
& Intercept[1] & 27.699 & 11.252 & 6.060 & 0.014 & - \\
& Intercept[2] & 29.253 & 11.313 & 6.687 & 0.010 & - \\
& Log_slope & -2.085 & 1.025 & 4.135 & 0.042 & 0.124 \\
& Jun_NDVI & -8.320 & 3.055 & 7.417 & 0.007 & $<0.001$ \\
& MayTx & -1.098 & 0.548 & 4.011 & 0.045 & 0.333 \\
\hline
\end{tabular}

${ }^{\mathrm{z}}$ Model selection was based on backward elimination with effect significant level at $P \leq 0.05$.

TABLE 3. Summaries of soybean sudden death syndrome (SDS) (caused by Fusarium virguliforme occurrence, F. virguliforme soil density, field distance to the nearest flowline (DNF), and field slope for three groups of soybean fields surveyed in 2014

\begin{tabular}{llcccccc}
\hline Group & SDS risk $^{\mathrm{u}}$ & SDS prevalence & Average SDS severity & Average density $^{\mathrm{v}}$ & Highest density $^{\mathrm{w}}$ & Average slope $^{\mathrm{x}}$ & Average distance to flowline $^{\mathrm{y}}$ \\
\hline $\mathrm{H}$ & High & $80 \%$ & 1.73 & Not tested $^{\mathrm{z}}$ & Not tested & 1.27 & 350.75 \\
$\mathrm{R}$ & Moderate & $75 \%$ & 1.27 & 49,984 & 141,542 & 1.04 & 492 \\
$\mathrm{~L}$ & Low & Corn field & N/A & 3,775 & 10,086 & 0.94 & 492.44 \\
\hline
\end{tabular}

u Estimated SDS risks based on historical normalized difference vegetation index data analyses results Freq_Even. Higher Freq_Even values were considered high SDS risks.

v Number of $F$. virguliforme cells per gram of soil, based on quantitative polymerase chain reaction tests.

" Significant difference $(P<0.001)$ of $F$. virguliforme density was detected between groups $\mathrm{R}$ and $\mathrm{L}$, based on Welch's $t$ test.

x In degrees. No significant difference $(P=0.519)$ of slope was detected among groups $\mathrm{H}, \mathrm{R}$, and $\mathrm{L}$, based on Wilcoxon's test.

y No significant difference $(P=0.144)$ of DNF was detected among groups $\mathrm{H}, \mathrm{R}$, and $\mathrm{L}$, based on Wilcoxon's test.

${ }^{\mathrm{z}}$ Soil samples were not collected in these fields.

TABLE 4. Variables showed significant correlation $(P<0.1)$ with the occurrence level of soybean sudden death syndrome caused by Fusarium virguliforme across all surveyed soybean fields in 2014

\begin{tabular}{llrr}
\hline Variables & \multicolumn{1}{c}{ Variable descriptions } & Spearman $\rho, P$ value & Linear correlation, $P$ value \\
\hline Jun16_NDVI & Normalized difference vegetation index (NDVI on June 16 & $0.336,0.009$ & $0.344,0.006$ \\
Jun23_NDVI & NDVI on June 23 & $0.353,0.006$ & $0.373,0.003$ \\
Jun30_NDVI & NDVI on June 30 & $0.364,0.004$ & $0.330,0.009$ \\
Jun_NDVI & Average NDVI in June 16 to 30 & $0.422,<0.001$ & $0.170,0.195$ \\
Log_slope & Logarithmic average slope of soybean field (degree) & $-0.256,0.049$ & $0.451,<0.001$ \\
Log_DNF & Logarithmic distance to the nearest flowline (meter) & $0.304,0.018$ & $-0.147,0.098$ \\
AprTx & Monthly maximum temperature in April $\left({ }^{\circ} \mathrm{C}\right)$ & $0.180,0.168$ & $0.285,0.027$ \\
MayTn & Monthly minimum temperature in May $\left({ }^{\circ} \mathrm{C}\right)$ & $0.368,0.004$ & $0.218,0.095$ \\
MayTx & Monthly maximum temperature in May $\left({ }^{\circ} \mathrm{C}\right)$ & $0.231,0.075$ & $0.353,0.006$ \\
JulTn & Monthly minimum temperature in July $\left({ }^{\circ} \mathrm{C}\right)$ & $-0.144,0.273$ & $0.280,0.031$ \\
JunPrcp & Monthly total precipitation in June (millimeter) & $0.232,0.075$ & $-0.242,0.062$ \\
JulPrcp & Monthly total precipitation in July (millimeter) & & $0.235,0.071$ \\
\hline
\end{tabular}


model 1 in Table 5 to show the general trend of potential SDS occurrence in 2014 in Iowa (Fig. 3). The risk map showed a clear trend that south and central Iowa had much higher SDS risks than the northeast, matching our field survey data.

The ordinal regression tree analysis result (Fig. 4) suggested that Jun_NDVI, maximum temperature in May, and field slope could be applied to differentiate SOL, using the surveyed soybean fields. This result was similar to the ordinal logistic regression model 2. The most significant variable was Jun_NDVI, consistent with the results of correlation analyses in Table 4. High maximum temperature in May would promote higher SDS occurrence, as would field slope.

\section{DISCUSSION}

In this study, field surveys for SDS were conducted at multiple locations across different regions in Iowa and the disease occurrence related to soybean canopy NDVI, $F$. virguliforme density in the soil, weather, and several field-specific environmental factors were modeled. The results showed that several field-specific factors were significantly correlated with SDS occurrence and $F$. virguliforme densities. In general, the survey results were consistent with the SDS risks assessed based on the historical NDVI analyses based on satellite imagery and agreed with our hypotheses regarding the potential associations among NDVIs, several field-specific environmental factors, and occurrence of SDS. Ordinal logistic regression and regression tree analyses results further identified the effects of several important factors, such as spring temperatures, NDVI in June, and field slope. This, indeed, provided strong evidence that RS data could be useful in SDS risk assessment at both regional and farm scales. The information will be helpful to develop more sophisticated SDS predictive and risk assessment models for better SDS management, especially for preseason decision making.

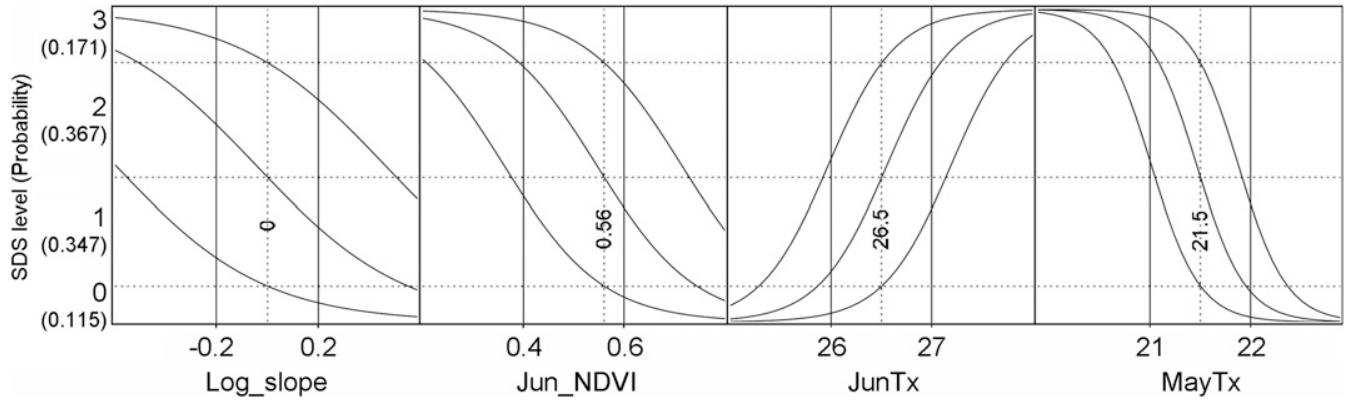

Fig. 2. A profiler showing the effects of slope, Jun_NDVI (normalized difference vegetation index), JunTx, and MayTx in model 1 in Table 5 to the probabilities of occurrence level of soybean sudden death syndrome (SDS) caused by Fusarium virguliforme. JunTx had a negative effect, i.e., high JunTx reduced the probabilities of high disease levels, while the other three factors were positive to the disease. The probabilities on the left under different SDS levels were based on the given values of predictive variables marked by the vertical dash lines in the figure.

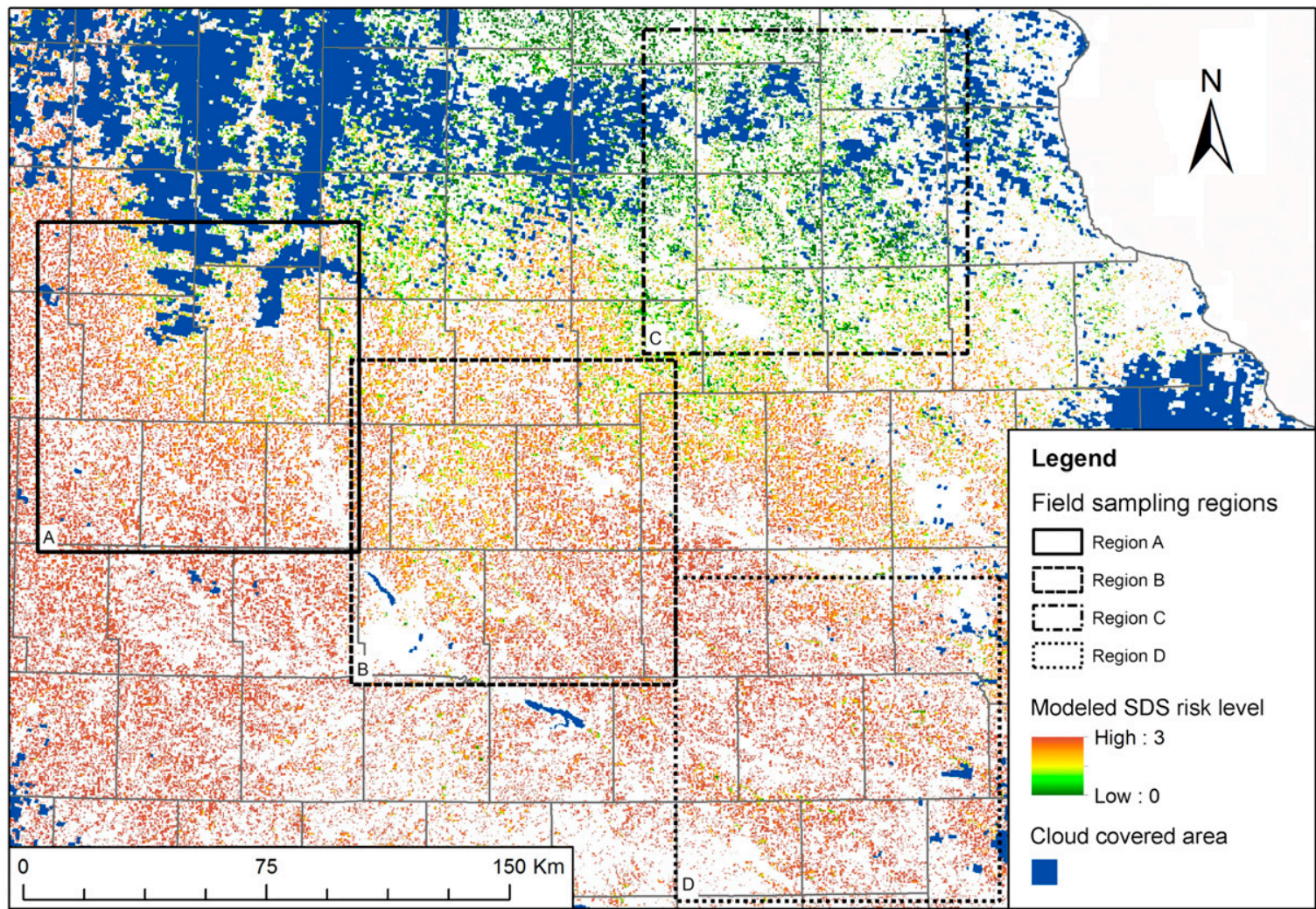

Fig. 3. A map of modeled disease risks at 250-m resolution based on model 1 in Table 5 showing the potential trend of soybean sudden death syndrome occurrence caused by Fusarium virguliforme in 2014 in Iowa. 
In Table 1, the percentage of each Freq_Even value to the total fields in different regions was different and region $\mathrm{A}$ had the highest percentage of high Freq_Even values. The Freq_Even values decreased from region A to D. Meanwhile, region A showed striking trends in near and slope analyses (Table 2), while, in the other three regions, such trends were less significant or insignificant. These differences could be the results of different distribution patterns of flowline and terrain features. As shown in Figure 5, the density of flowlines in region A was much lower than that in the other regions, which was why the distance to the nearest flowline of a field in region $A$ (>600 meters) was, on average, greater than that in the other regions (in a range of 260 to 390 meters).

Geographically, the majority of region A and part of region B are located in the Des Moines lobe (Fig. 5, the area with an apparently lower flowline density), a region that resulted from prehistoric glacier activities, with many shallow wetlands that were drained for agricultural uses (Prior 1991). These wetlands may receive water recharges from snowmelt and ground water throughout the season, with a more stable water supply than that in fields fed by precipitations. Thus, the water distribution these areas would provide better conditions for SDS and other foliar diseases in the growing season. Indeed, in region A, 11 of 12 surveyed fields had SDS occurrence in 2014, which was a SDS prevalence higher than the SDS prevalence in region $\mathrm{B}(83.87 \%)$ and $\mathrm{C}(53.85 \%)$, excepting region $\mathrm{D}$ with only four fields surveyed. Among the five fields with the highest $F$. virguliforme population ( $>100,000$ cells per gram of soil), four were in the Des Moines lobe region (two in region A, two in region $\mathrm{B}$, and one in region $\mathrm{C}$ ). Given the similar $F$. virguliforme density ranges in region $\mathrm{A}, \mathrm{B}$, and $\mathrm{C}$, it seemed that region $\mathrm{A}$ would have more favorable conditions for SDS occurrences.

MODIS satellite imagery has a 250-m spatial resolution, which may mask the effects of a flowline on SDS risk assessment in a field, if the distance is close to the spatial resolution of NDVI data, e.g., in regions $\mathrm{C}$ and $\mathrm{D}$. To explore the feasibility and ability of satellite imagery at a finer spatial resolution for more detailed SDS risk analyses at the field level, we used Landsat 5 and 7 imager sources to select areas for the same analyses as those performed for the eMODIS data.

First, historical Landsat imagery (Fig. 5, scene path 26 and row 31 with a real coverage) in days 214 to 230 in 2002, 209 to 233 in 2006, 215 to 231 in 2008,212 to 228 in 2010, and 215 to 231 in 2014 were used to generate a frequency of significant NDVI decrease (10 to $20 \%$ in 16 days in $2002,2008,2010$, and 2014 or 15 to $20 \%$ in 24 days in 2006) for each soybean field, i.e., a Landsat imagery pixel covering a $30 \times 30-\mathrm{m}$ area of soybean field, similar to Freq_Even derived from eMODIS data described before. Due to a high proportion of cloud cover, NDVI data in 2004 and 2012 were not used. Meanwhile, compared with the band designations of Landsat 5 and 7 for red $(0.63$ to $0.69 \mu \mathrm{m})$ and near infrared $(0.77$ to $0.90 \mu \mathrm{m})$, MODIS has slightly different wavelength ranges in red (0.62 to $0.67)$ and near infrared ( 0.841 to 0.876$)$, which are closer to those in Landsat 8 , red ( 0.64 to $0.67 \mu \mathrm{m})$ and near infrared ( 0.85 to $0.88 \mu \mathrm{m})$. Overall, Landsat 8 data, not available before 2013, have a better agreement with MODIS NDVIs than those of Landsat 7 (Ke et al. 2015). As we used the percentage of NDVI decrease based on imagery from the same band designations in the analyses, the potential negative effects resulting from the differences of NDVI measurements would be minimal.

In total, 27,372 soybean fields were retrieved, and we arbitrarily selected 19,020 of them, located in region E (Fig. 5). This region covered an area in which the density of flowline is similar to regions $\mathrm{C}$ and D but apparently higher than that in region $\mathrm{A}$ in the Des Moines lobe. Previously with eMODIS data, we did not detect significant differences for DNF in region C and D (Table 2), possibly due to the mask effect of low spatial resolution. With the Landsat imagery, Wilcoxon's test (Table 6) did detect significant differences for DNF for the fields among frequencies of 0,1 , and 2 . This trend was similar to that in region A based on eMODIS data
(Table 2). Considering region $\mathrm{E}$ is located geographically among regions $\mathrm{B}, \mathrm{C}$, and $\mathrm{D}$, with a similar flowline density, this trend may be applied to these regions as well. These results indicated that Landsat imagery did have similar or higher abilities in the assessment of spatial patterns of disease risks at the field scale, especially in rugged terrains, such as in regions $C$ and $D$.

For slope, the results based on Landsat data were not consistent to any of those found for the four regions in Table 2, though there was a significant difference detected between frequencies 0 and 2 . Slope is often associated with flowline and sink (a lower area) distribution within a field. Different flowlines, e.g., rivers, creeks, or drainages, may have significantly different effect zones or magnitudes to the nearby fields and disease occurrence. Also these effects would certainly interact with soil type, farming practices, or other factors, e.g., roads and perhaps slope direction. Indeed, spatial patterns of slope associated with fields of different NDVI changes, including the results based on Landsat imagery, were not always as significant and consistent in the other regions as it was in region $\mathrm{A}$. The results presented in this study had no other detailed field information considered to differentiate the effects of different flowlines. In future, it would be interesting to focus on smaller areas in region A, where both flowline and slope showed correlations with NDVIs, and use satellite data of finer resolutions to further examine how these factors interact with disease occurrence.

Given the results above, the advantages and limitations of Landsat imagery are apparent. Higher spatial resolution of Landsat data provide better ability to detect patterns at a finer spatial scale, important for disease risks associated with terrain features. Yet, its 16-day revisiting time and the data gaps in Landsat 7 products hinder the analyses for disease temporal dynamics in more fields. In future, given more available Landsat 8 data, similar analyses could be further improved, integrated with MODIS data.

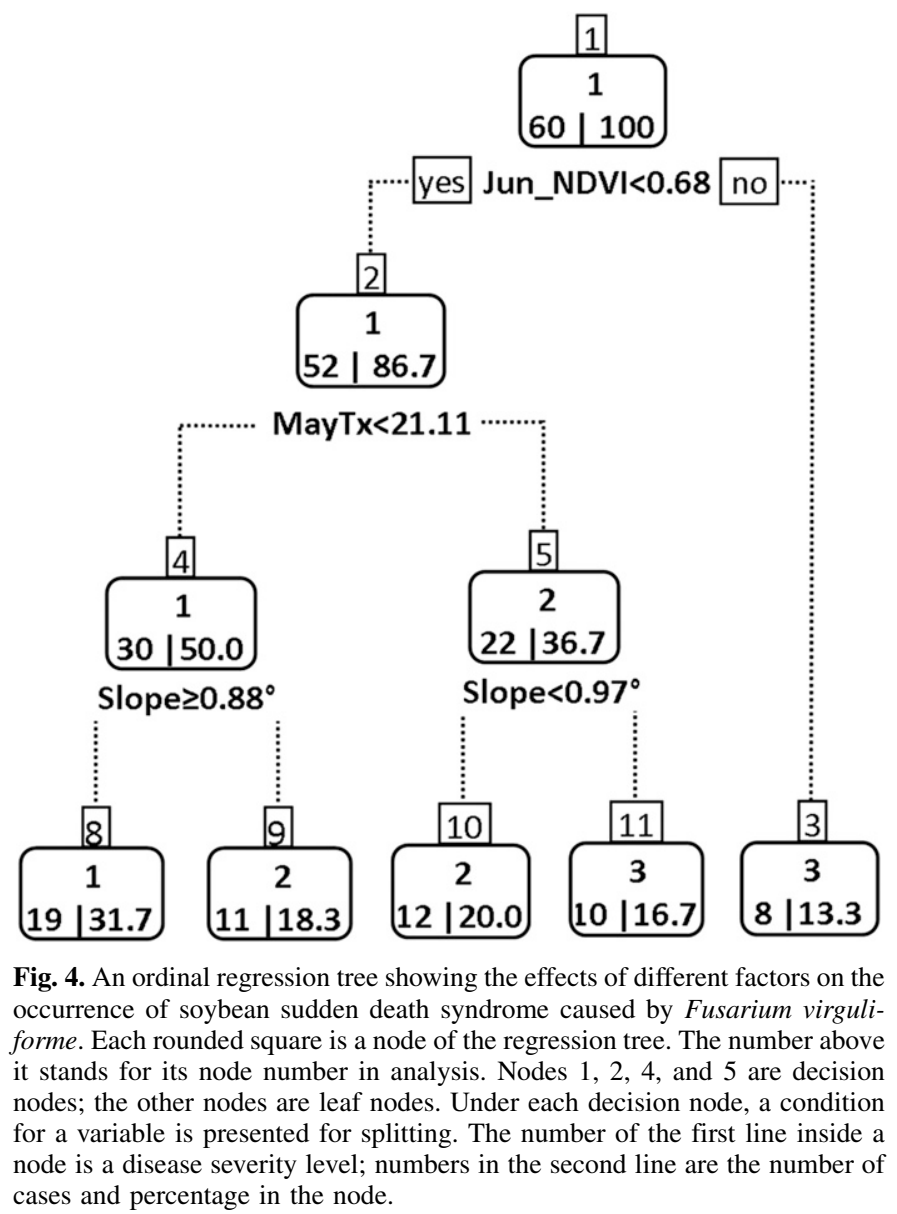

Vol. 106, No. 8, 2016 849 
The field survey results in Table 3 provided strong evidence that satellite imagery could provide valuable information for disease risks at a farm scale. For example, hypothetically, the fields in group $\mathrm{H}$ with high Freq_Even values $(\geq 2)$ should have higher SDS risks compared with group $\mathrm{R}$ (hypothetically moderate risks) and group $\mathrm{L}$ (hypothetically low risks). Indeed, on average, we observed higher SDS level in group $\mathrm{H}$ than that in group $\mathrm{R}$, while $F$. virguliforme densities in group L were very low compared with those in group R. Even though slope and DNF in the three groups did not differ statistically, probably due to small sample size and high variations, the trends generally supported our hypotheses and previous field observations, i.e., SDS was more severe in rolling fields and areas close to flowlines.

Among the factors listed in Table 4, Jun_NDVI had the highest and consistent correlations with SDS, indicating a strong influence of this period to the disease. June is a key growth stage for soybean canopy development. In Nebraska, NDVI was found to be the most sensitive to soybean gLAI less than $2 \mathrm{~m}^{2} / \mathrm{m}^{2}$ (NDVI value about 0.7), which is from planting to the flowering stage (Nguy-Robertson et al. 2012). Thus, low NDVIs in middle to late June around the flowering stage would be a reliable indicator for a late planting.

SDS is well-known for being favored by early planting under cool and wet weather (Hershman et al. 1990; Scherm and Yang 1996; Wrather et al. 1995). More evidence could be found from the estimated annual yield losses of soybean by SDS in the United States (Koenning and Wrather 2010; Wrather and Koenning 2006, 2009) (other data from the Illinoise Crop Science Extension and Outreach at http://extension.cropsciences.illinois.edu/fieldcrops/ diseases/yield_reductions.php) and the crop progress reports by the United States Department of Agriculture (USDA). For example, the dates of 30 to $50 \%$ of the soybean fields planted across Iowa were significantly negatively correlated $(P<0.01$ for both percentages) with the annual yield losses by SDS in the United States in 1996 to 2014. As Iowa is a major soybean-producing state with multiple major SDS epidemics in history, such correlation is of no surprise. And these historical data analyses were highly consistent with our findings showing significantly positive correlations of NDVIs in June with SDS occurrence in August in 2014. Such correlation of NDVI in a soybean key growth stage and SDS would illuminate future development of more comprehensive disease predictive models for SDS, late season disease management, and yield assessment.

AprTx and MayTx both had high and consistent positive correlations with SOL. However, AprTx was eliminated by backward selection in the logistic regression, probably due to high correlation

TABLE 6. Summary of near and slope analyses for different frequency values of significant soybean canopy normalized difference vegetation index drop in early August in five years (2002, 2006, 2008, 2010, and 2014), based on Landsat 5 and 7 imagery for the selected fields in region $\mathrm{E}$

\begin{tabular}{lccrr}
\hline & \multicolumn{3}{c}{ Frequency $^{\mathrm{x}}$} & \\
\cline { 2 - 4 } & 0 & 1 & 2 & $P$ value $^{\mathrm{y}}$ \\
\hline Number of fields & 16,841 & 2,091 & 87 & $\mathrm{NA}$ \\
$\begin{array}{l}\text { Distance to the nearest } \\
\text { flow line (meters) }\end{array}$ & $265.27 \mathrm{a}^{\mathrm{z}}$ & $256.39 \mathrm{~b}$ & $214.94 \mathrm{c}$ & $<0.001$ \\
Slope (degrees) & $1.43 \mathrm{a}$ & $1.41 \mathrm{ab}$ & $1.29 \mathrm{~b}$ & 0.045 \\
\hline
\end{tabular}

$x$ Only one field had a frequency value of 3 and was excluded.

y $P$ values for the $\chi^{2}$ approximation of Wilcoxon/Kruskal-Wallis one-way test.

${ }^{\mathrm{z}}$ Nonparametric comparisons for each pair of frequency values using Wilcoxon method. Different letters indicating significant difference of medians of the corresponding variable.

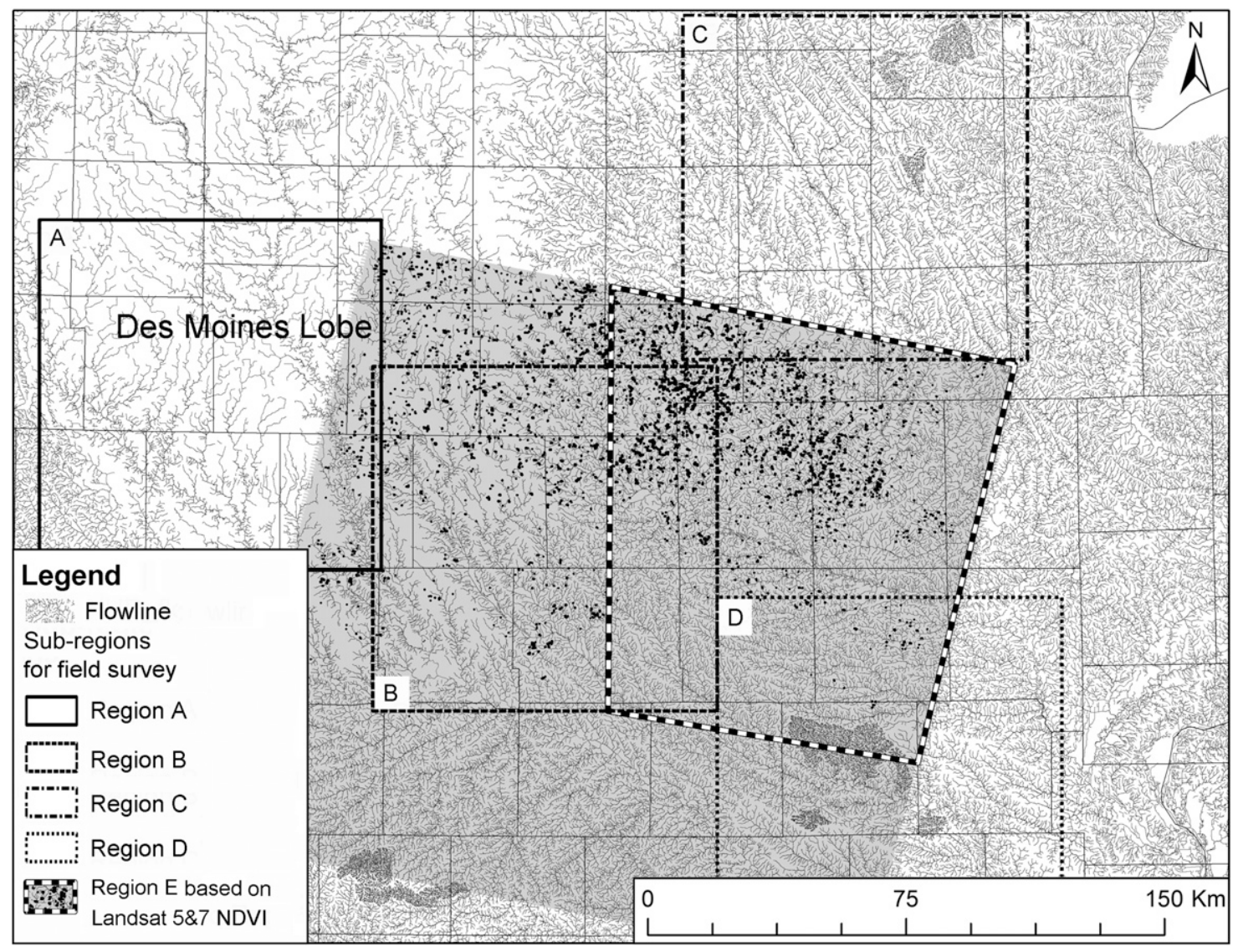

Fig. 5. Flowline densities in the surveyed regions in Iowa and region E, in which soybean fields were selected based on historical Landsat 5 and 7 imagery in 2002 , 2006, 2008, 2010, and 2014, to determine spatial patterns of the distance to the nearest flowline and slope of the fields associated with different frequencies of significant normalized difference vegetation index decrease in early August. 
with MayTx $(r=0.9142)$. In fact, if arbitrarily chosen to replace MayTx, AprTx could result in similar models to those listed in Table 5 with slightly less-predictive power (results not shown), and AprTx had a similar effect to MayTx, indicating the favorable influence of a warm spring to SDS. Interestingly, JunTx did not have high correlations with SDS $(r=0.1626$ and $\rho=0.1175)$, yet it was selected in model 1 and its effect was high, as well, compared with MayTx (Table 5; Fig. 2). For example, the probabilities for SDS levels 2 and 3 were 0.367 and 0.171 , respectively (Fig. 2). If JunTx increases by $1^{\circ} \mathrm{C}$, to 27.5 , then these probabilities will decrease to 0.046 and 0.011 , respectively. If MayTx decreases by $1^{\circ} \mathrm{C}$, to 20.5 , these probabilities will decrease to 0.014 and 0.003 , respectively.

Maximum temperatures showed stronger influences to SDS compared with the minimum temperature values, which were all eliminated in the modeling. Actually, mean temperatures could be used for the logistic regression, resulting in similar but lessdesirable models (results not shown). The reason for such strong influences from the maximum temperatures could have resulted from the weather pattern in May and June. Soybean is mainly planted in May in Iowa. A higher average maximum temperature in May means more clear days, which allow more work days for heavy machinery in the field, a key factor for early planting. May 2014 in Iowa was relatively dry with near-normal temperatures (data from the National Climatic Data Center [NCDC]), leaving a fairly long period for field work. According to the crop progress report by the USDA, $50 \%$ of the soybean crop was planted in Iowa by May 9 in 2014, making a relatively early planting season. In the meantime, due to no-till and conservation tillage, soil temperatures would not increase as fast as daily maximum temperature does (Triplett and Dick 2008), leaving a cool and moist soil environment still favorable for F. virguliforme. Furthermore, in April 2014, Iowa received much above normal (ranked fourteenth in 121 years) precipitation (data from NCDC), providing high soil moisture for SDS during the planting season.

Similarly, in June, a high maximum temperature implies less precipitation. For example, the correlation coefficient of the maximum temperature and precipitation in June in 2014 was $-0.133(P=$ 0.309 ) across the 60 surveyed fields in this study. Less precipitation may reduce the chances of SDS epidemics, according to previous observations and reports (Leandro et al. 2013). Interestingly, both June and July rainfall were not significant in the logistic models, even though they should have a strong effect to SDS (Leandro et al. 2013). Actually, in June 2014, Iowa received much more than normal precipitation, ranked third in 121 years, while July precipitation was near normal. Thus, the negative correlations of June precipitation with SDS (Table 4), though not statistically significant, might be caused by the excessive precipitation that was much more than what was needed for SDS epidemics.

The SDS risk map based on model 1 for 2014 showed a clear low-risk region in northeastern Iowa, where region $\mathrm{C}$ was located. Indeed, in this region, we only observed low-level SDS in the field, though the $F$. virguliforme density level was not low at all. Meanwhile, the modeled disease risks in region $\mathrm{D}$ was high, which could help explain a relatively high SDS level (average SOL at 1.75) in this region, though its pathogen density (average $F$. virguliforme at 14,422 ) was the lowest among the four regions. Nonetheless, caution must be taken when using such a risk map, as they only provide a general trend of risk distribution, given they were based on modeled reanalysis weather data at a very low spatial resolution ( 0.25 degrees, in this case). The potential effects of rainfall in spring and summer were not included in the models, probably due to the extreme weather pattern in 2014 or other factors that were out of the scope of this study. Given the current models, more work could be done with historical rainfall and yield loss estimations due to SDS to further investigate the role of rainfall in SDS risk modeling.

The effects of slope may be associated with flowlines, drainages, or water accumulation within field depressions that provide higher soil moisture, thus favoring disease occurrence. Another possible effect of slope is that, in early spring, $F$. virguliforme propagules on crop residuals may spread much easier over the field, carried by running water due to slope. Also, compared with other factors that may interact with SDS occurrence, such as precipitations, planting time, or variety selection, slope is a more constant factor that exerts influence to a field over time. It may play an important role in disease risk assessment at the farm scale using farm-specific information and deserves further investigation in future.

Using culture-dependent techniques, Rupe et al. (1997) reported an $F$. virguliforme population density range of 1,191 to $4,399 \mathrm{CFU}$ per gram of dried soil in growing seasons in 1989 to 1992 in Arkansas, and the highest population density appeared around the harvest stage of each year. Here, we detected relatively higher $F$. virguliforme soil densities, presumably due to the higher sensitivity of the DNA-based approach, i.e., qPCR. It is also possible that the fertile soils in Iowa generally harbor more $F$. virguliforme than those from Arkansas. In Wisconsin, using a similar qPCR approach, Marburger et al. (2015) reported an $F$. virguliforme soil population density range of 0 to 66,887 , with an average of 25,090 spores per gram of soil, which was much lower than our results, though the magnitude was similar.

We did not monitor $F$. virguliforme densities over the whole growing season in 2014 for population dynamics. However, soil sampling was conducted in late March 2015 at 48 different locations in region B for $F$. virguliforme population tests, using the same qPCR approach. These locations included 20 soybean fields of high Freq_Even, 18 corn fields selected in the manner to those in group L, based on their NDVIs in 2012, and another eight soybean fields in group H surveyed in 2014, two sampling locations in arbitrarily selected forest soil as negative controls, and the Hinds research farm. Seven corn fields of 18 had a positive $F$. virguliforme detection, ranging from 112 to 6,140, whereas four soybean fields of 20 had a positive $F$. virguliforme detection, ranging from 319 to 4,213. All eight fields that had SDS occurrence in 2014 had $F$. virguliforme detection ranging from 580 to 7,775 , and the highest F. virguliforme density occurred in a field with moderate SDS occurrence (level 2) in 2014. As expected, the two forest soil samples had no $F$. virguliforme detection. $F$. virguliforme in the Hinds farm soil was 580, compared with 80,162 in 2014 summer. It seemed that $F$. virguliforme densities could change rapidly in different seasons and corn fields may provide a better environment for $F$. virguliforme survival with more crop residuals, consistent to a previous report by Yang and Navi (2010). Due to limited resources, the dynamics of $F$. virguliforme population was not a major objective in this study. Yet, its associations with certain fieldspecific environmental factors is important for SDS risk assessment and should be further investigated in the future.

\section{ACKNOWLEDGMENTS}

This study was funded by check-off dollars from Iowa Soybean Association (ISA), and we are grateful to ISA on-farm network staff for assistance in the field survey. We also thank the China Scholarship Council for financial support for the first author to visit Iowa State University and conduct this research.

\section{LITERATURE CITED}

Al-Kaisi, M. M., Elmore, R. W., Guzman, J. G., Hanna, H. M., Hart, C. E., Helmers, M. J., Hodgson, E. W., Lenssen, A. W., Mallarino, A. P., Robertson, A. E., and Sawyer, J. E. 2013. Drought impact on crop production and the soil environment: 2012 experiences from Iowa. J. Soil Water Conserv. 68:19A-24A.

Aoki, T., O’Donnell, K., Homma, Y., and Lattanzi, A. R. 2003. Sudden-death syndrome of soybean is caused by two morphologically and phylogenetically distinct species within the Fusarium solani species complex- $F$. virguliforme in North America and F. tucumaniae in South America. Mycologia 95:660-684.

Aoki, T., Tanaka, F., Suga, H., Hyakumachi, M., Scandiani, M. M., and O’Donnell, K. 2012. Fusarium azukicola sp. nov., an exotic azuki bean root-rot pathogen in Hokkaido, Japan. Mycologia 104:1068-1084. 
Apan, A., Held, A., Phinn, S., and Markley, J. 2004. Detecting sugarcane 'orange rust'disease using EO-1 hyperion hyperspectral imagery. Int. J. Remote Sens. 25:489-498.

Ashourloo, D., Mobasheri, M., and Huete, A. 2014a. Developing two spectral disease indices for detection of wheat leaf rust (Puccinia triticina). Remote Sens. 6: 4723-4740.

Ashourloo, D., Mobasheri, M., and Huete, A. 2014b. Evaluating the effect of different wheat rust disease symptoms on vegetation indices using hyperspectral measurements. Remote Sens. 6: 5107-5123.

Asrar, G. Q., Fuchs, M., Kanemasu, E. T., and Hatfield, J. L. 1984. Estimating absorbed photosynthetic radiation and leaf area index from spectral reflectance in wheat. Agron. J. 76:300-306.

Brar, H. K., Swaminathan, S., and Bhattacharyya, M. K. 2011. The Fusarium virguliforme toxin FvTox1 causes foliar sudden death syndrome-like symptoms in soybean. Mol. Plant-Microbe Interact. 24:1179-1188.

Breiman, L., Friedman, J. H., Olshen, R. A., and Stone, C. J. 1984. Classification and Regression Trees. Wadsworth, Belmont, CA.

Carlson, T. N., and Ripley, D. A. 1997. On the relation between NDVI, fractional vegetation cover, and leaf area index. Remote Sens. Environ. 62: 241-252.

Cho, J. H., Rupe, J. C., Cummings, M. S., and Gbur, E. E., Jr. 2001. Isolation and identification of Fusarium solani f. sp. glycines from soil on modified Nash and Snyder's medium. Plant Dis. 85:256-260.

Daughtry, C. S. T., Gallo, K. P., Goward, S. N., Prince, S. D., and Kustas, W. P. 1992. Spectral estimates of absorbed radiation and phytomass production in corn and soybean canopies. Remote Sens. Environ. 39:141-152.

Esquerdo, J. C. D. M., Zullo Júnior, J., and Antunes, J. F. G. 2011. Use of NDVI/AVHRR time-series profiles for soybean crop monitoring in Brazil. Int. J. Remote Sens. 32:3711-3727.

Fox, J. 2003. Effect displays in R for generalised linear models. J. Stat. Softw. $8: 1-27$

Fox, J., and Hong, J. 2009. Effect displays in R for multinomial and proportional-odds logit models: Extensions to the effects package. J. Stat. Softw. 32:1-24.

Franke, J., and Menz, G. 2007. Multi-temporal wheat disease detection by multi-spectral remote sensing. Precis. Agric. 8:161-172.

Galimberti, G., Soffritti, G., and Di Maso, M. 2012. Classification trees for ordinal responses in R: The rpartScore Package. J. Stat. Softw. 47:1-25.

Gesch, D., Oimoen, M., Greenlee, S., Nelson, C., Steuck, M., and Tyler, D. 2002. The national elevation dataset. Photogramm. Eng. Remote Sensing 68:5-11.

Gesch, D. B. 2007. Pages 99-118 in: The National Elevation Dataset. Digital Elevation Model Technologies and Applications: The DEM Users Manual, 2nd ed.. D. Maune, ed. American Society for Photogrammetry and Remote Sensing, Bethesda, MD.

Hartman, G. L., Chang, H. X., and Leandro, L. F. 2015. Research advances and management of soybean sudden death syndrome. Crop Prot. 73: 60-66.

Hartman, G. L., Noel, G. R., and Gray, L. E. 1995. Occurrence of soybean sudden death syndrome in East-Central Illinois and associated yield losses. Plant Dis. 79:314-318.

Hershman, D. E., Hendrix, J. W., Stuckey, R. E., Bachi, P. R., and Henson, G. 1990. Influence of planting date and cultivar on soybean sudden death syndrome in Kentucky. Plant Dis. 74:761-766.

Hosmer, D., Sturdivant, R., and Lemeshow, S. 2013. Applied logistic regression. John Wiley \& Sons, Inc., Hoboken, NJ.

Hughes, T. J., O’Donnell, K., Sink, S., Rooney, A. P., Scandiani, M. M., Luque, A., Bhattacharyya, M. K., and Huang, X. 2014. Genetic architecture and evolution of the mating type locus in fusaria that cause soybean sudden death syndrome and bean root rot. Mycologia 106:686-697.

Jackson, R. D. 1986. Remote sensing of biotic and abiotic plant stress. Annu. Rev. Phytopathol. 24:265-287.

Jenkerson, C. B., Maiersperger, T. K., and Schmidt, G. L. 2010. eMODIS: A user-friendly data source. Page 10 in: U.S. Geological Survey Open-File Report 2010-1055. U.S. Geological Survey's Earth Resources Observation and Science Center, Sioux Falls, SD.

Jones, R. A. C. 2014. Trends in plant virus epidemiology: Opportunities from new or improved technologies. Virus Res. 186:3-19.

Kandel, Y. R., Haudenshield, J., Srour, A. Y., Islam, K. T., Fakhoury, A. M., Santos, P., Wang, J., Chilvers, M. I., Hartman, G., Malvick, D., Floyd, C. M., Mueller, D., and Leandro, L. 2015. Multi-laboratory comparison of quantitative PCR assays for detection and quantification of Fusarium virguliforme from soybean roots and soil. Phytopathology 105:1601-1611.

Ke, Y., Im, J., Lee, J., Gong, H., and Ryu, Y. 2015. Characteristics of Landsat 8 OLI-derived NDVI by comparison with multiple satellite sensors and in-situ observations. Remote Sens. Environ. 164:298-313.

Knipling, E. B. 1970. Physical and physiological basis for the reflectance of visible and near-infrared radiation from vegetation. Remote Sens. Environ. $1: 155-159$.
Koenning, S. R., and Wrather, J. A. 2010. Suppression of soybean yield potential in the continental United States by plant diseases from 2006 to 2009. Plant Health Progress doi:10.1094/PHP-2010-1122-01-RS

Kolander, T. M., Bienapfl, J. C., Kurle, J. E., and Malvick, D. K. 2012. Symptomatic and asymptomatic host range of Fusarium virguliforme, the causal agent of soybean sudden death syndrome. Plant Dis. 96: 1148-1153.

Leandro, L. F. S., Robertson, A., Mueller, D. S., and Yang, X. B. 2013. Climatic and environmental trends observed during epidemic and nonepidemic years of soybean sudden death syndrome in Iowa. Plant Health Progress doi:10.1094/PHP-2013-0529-01-RS

Li, X., Lee, W. S., Li, M., Ehsani, R., Mishra, A. R., Yang, C., and Mangan, R. L. 2015. Feasibility study on Huanglongbing (citrus greening) detection based on WorldView-2 satellite imagery. Biosystems Eng. 132:28-38.

Li, X., and Yang, X. B. 2013. Using satellite remote sensing in crop stress assessment in Iowa. Acta Phytopathologica Sin.: 171.

Marburger, D. A., Venkateshwaran, M., Conley, S. P., Esker, P. D., Lauer, J. G., and Ané, J. 2015. Crop rotation and management effect on Fusarium spp. populations. Crop Sci. 55:365-376.

Martinelli, F., Scalenghe, R., Davino, S., Panno, S., Scuderi, G., Ruisi, P., Villa, P., Stroppiana, D., Boschetti, M., and Goulart, L. R. 2014. Advanced methods of plant disease detection. A review. Agron. Sustain. Dev. 35:1-25.

Mbofung, G. C. Y., Fessehaie, A., Bhattacharyya, M. K., and Leandro, L. F. S. 2011. A new TaqMan real-time polymerase chain reaction assay for quantification of Fusarium virguliforme in soil. Plant Dis. 95: 1420-1426.

Mirik, M., Jones, D. C., Price, J. A., Workneh, F., Ansley, R. J., and Rush, C. M. 2011. Satellite remote sensing of wheat infected by wheat streak mosaic virus. Plant Dis. 95:4-12.

Moran, S. M., Inoue, Y., and Barnes, E. M. 1997. Opportunities and limitations for image-based remote sensing in precision crop management. Remote Sens. Environ. 61:319-346

Navi, S. S., and Yang, X. B. 2008. Foliar symptom expression in association with early infection and xylem colonization by Fusarium virguliforme (formerly $F$. solani f. sp. glycines), the causal agent of soybean sudden death syndrome. Plant Health Progress doi:10.1094/PHP-2008-0222-01-RS

Nguy-Robertson, A., Gitelson, A., Peng, Y., Viña, A., Arkebauer, T., and Rundquist, D. 2012. Green leaf area index estimation in maize and soybean: combining vegetation indices to achieve maximal sensitivity. Agron. J. 104: 1336-1347.

Nilsson, H. E. 1995. Remote sensing and image analysis in plant pathology. Can. J. Plant Pathol. 17:154-166.

Njiti, V. N., Doubler, T. W., Suttner, R. J., Gray, L. E., Gibson, P. T., and Lightfoot, D. A. 1998. Resistance to soybean sudden death syndrome and root colonization by Fusarium solani f. sp. glycine in near-isogenic lines. Crop Sci. 38:472-477.

Nutter, F. W., Jr., van Rij, N., Eggenberger, S. K., and Holah, N. 2010. Spatial and temporal dynamics of plant pathologens. Pages 27-50 in: Precision Crop Protection-the Challenge and Use of Heterogeneity E. C. Oerke, R. Gerhards, G. Menz, and R. Sikora, eds. Springer, New York.

Prior, J. C. 1991. Landforms of Iowa. Iowa Department of Natural Resources, University of Iowa Press, Iowa City, IA.

R Core Team. 2014. R: A language and environment for statistical computing. $\mathrm{R}$ Foundation for Statistical Computing, Vienna, Austria. http://www. r-project.org/

Roy, K. W. 1997. Fusarium solani on soybean roots: nomenclature of the causal agent of sudden death syndrome and identity and relevance of F. solani form B. Plant Dis. 81:259-266.

Roy, K. W., Rupe, J. C., Hershman, D. E., and Abney, T. S. 1997. Sudden death syndrome of soybean. Plant Dis. 81:1100-1111.

Rumpf, T., Mahlein, A. K., Steiner, U., Oerke, E. C., Dehne, H. W., and Plümer, L. 2010. Early detection and classification of plant diseases with support vector machines based on hyperspectral reflectance. Comput. Electron. Agric. 74:91-99.

Rupe, J. C., Robbins, R. T., and Gbur, E. E. 1997. Effect of crop rotation on soil population densities of Fusarium solani and Heterodera glycines and on the development of sudden death syndrome of soybean. Crop Prot. 16: 575-580.

Scherm, H., and Yang, X. B. 1996. Development of sudden death syndrome of soybean in relation to soil temperature and soil water matric potential. Phytopathology 86:642-649.

Scherm, H., and Yang, X. B. 1999. Risk assessment for sudden death syndrome of soybean in the north-central United States. Agric. Syst. 59: 301-310.

Triplett, G. B., and Dick, W. A. 2008. No-tillage crop production: A revolution in agriculture! Agron. J.: S-153-S-167.

Tucker, C. J. 1979. Red and photographic infrared linear combinations for monitoring vegetation. Remote Sens. Environ. 8:127-150. 
USDA National Agricultural Statistics Service Cropland Data Layer. 2014. Published crop-specific data layer [online]. http://nassgeodata.gmu.edu/ CropScape/ USDA-NASS, Washington, D.C.

Venables, W. N., and Ripley, B. D. 2002. Modern Applied Statistics with S. Springer, New York.

Walthall, C., Dulaney, W., Anderson, M., Norman, J., Fang, H., and Liang, S. 2004. A comparison of empirical and neural network approaches for estimating corn and soybean leaf area index from Landsat ETM+ imagery. Remote Sens. Environ. 92:465-474.

Wang, J., Jacobs, J., and Chilvers, M. 2014. Management of soybean sudden death syndrome by seed treatment with fluopyram. Phytopatholgy 104:S3127.

Wang, J., Jacobs, J. L., Byrne, J. M., and Chilvers, M. I. 2015. Improved diagnoses and quantification of Fusarium virguliforme, causal agent of soybean sudden death syndrome. Phytopathology 105:378-387.

Williams, G. 2011. Data Mining with Rattle and R: The Art of Excavating Data for Knowledge Discovery. Springer Science \& Business Media, LLC, New York.
Wrather, J. A., Kendig, S. R., Anand, S. C., Niblack, T. L., and Smith, G. S. 1995. Effects of tillage, cultivar, and planting date on percentage of soybean leaves with symptoms of sudden death syndrome. Plant Dis. 79: 560-562.

Wrather, J. A., and Koenning, S. R. 2006. Estimates of disease effects on soybean yields in the United States 2003 to 2005. J. Nematol. 38:173.

Wrather, J. A., and Koenning, S. R. 2009. Effect of diseases on soybean yields in the United States 1996 to 2007. Plant Health Progress doi:10.1094/PHP2009-0401-01-RS

Xing, L. J., and Westphal, A. 2006. Interaction of Fusarium solani f. sp. glycines and Heterodera glycines in sudden death syndrome of soybean. Phytopathology 96:763-770.

Yang, X. B., and Navi, S. S. 2010. Good harvest in corn should help manage soybean SDS. Integrated Crop Management News. Paper 375. Iowa State University, Ames, IA. http://lib.dr.iastate.edu/cropnews/ 375 